\title{
The impact of the radial artery or the saphenous vein in addition to the bilateral internal mammary arteries on late survival: A propensity score analysis
}

\author{
Francesco Formica, MD, ${ }^{\mathrm{a}}$ Stefano D’ Alessandro, MD, FECTS, ${ }^{\mathrm{a}}$ Gurmeet Singh, MD, FRCSC, \\ Ana Maria Ciobanu, MD, ${ }^{\mathrm{c}}$ Luigi Amerigo Messina, MD, ${ }^{\mathrm{d}}$ Salvatore Scianna, MD, ${ }^{\mathrm{a}}$ and \\ Mario Moscatiello, MD
}

\begin{abstract}
Background: Long-term survival benefits of full arterial revascularization with radial artery (RA) used in addition to bilateral internal mammary arteries (BIMA) compared with saphenous vein (SV) used in addition to BIMA has not been clearly defined.
\end{abstract}

Methods: We retrospectively analyzed 660 3-vessel coronary artery disease subjects who received BIMA in addition to either RA $(n=206)$ or SV $(n=454)$ grafting in a period between June 1999 and November 2017. After propensity score matching, we obtained 190 matched pairs for analysis.

Results: In the matched population, in-hospital mortality occurred in 4 patients $(1 \%)$, with 2 deaths $(1.1 \%)$ in the BIMA + RA group and 2 deaths $(1.1 \%)$ in $\mathrm{BIMA}+\mathrm{SV}$ group $(P>.99)$. The median follow-up time was 9.2 years (interquartile range, 5.6-13 years) with a maximum follow-up time of 18.5 years. There was not a significant difference in long-term survival between the 2 groups over the follow-up period. Survival at 5, 10, and 15 years were $94.8 \pm 1.7 \%$, $83.7 \pm 3.1 \%$, and $78.6 \pm 3.9 \%$ in the BIMA + RA group and $96.2 \pm 1.4 \%$, $85.1 \pm 2.9 \%$, and $80.4 \pm 3.6 \%$ in the BIMA + SV group (stratified log-rank $P=.78$ ). Cox proportional hazard regression model was used to estimate that the use of RA in addition to BIMA did not affect the late mortality (propensity score adjusted hazard ratio, $1.05 ; 95 \%$ confidence interval, $0.62-1.79 ; P=.83$ ).

Conclusions: In a relatively small population of triple-vessel coronary artery disease, the use of RA as a third arterial conduit with BIMA did not confer a long-term survival benefit. (J Thorac Cardiovasc Surg 2019;158:141-51)

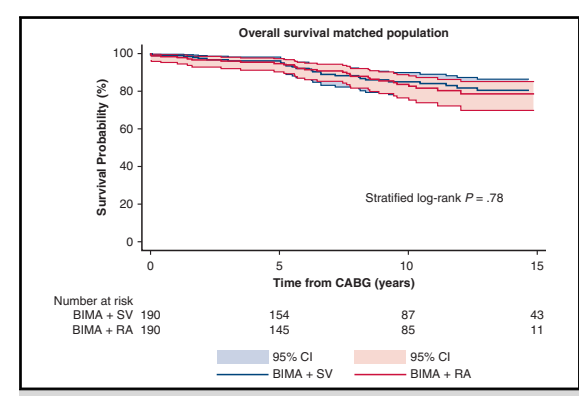

Comparison of survival probabilities in matched patients who underwent BIMA and RA versus BIMA and SV CABG.

\section{Central Message}

In triple-vessel disease coronary patients who underwent coronary surgery, radial artery used in addition to the bilateral internal mammary arteries did not confer better long-term survival compared with use of the saphenous vein.

\section{Perspective}

Long-term survival in triple-vessel coronary patients who underwent coronary artery bypass grafting surgery with BIMA with either radial artery or saphenous vein is comparable. Further longer-term studies with larger cohorts of patients are needed to show whether the radial artery should be preferred to saphenous vein as a third conduit to use in addition to the BIMA

See Commentaries on pages 152 and 154.
Coronary artery bypass grafting (CABG) is still recommended for patients with 3-vessel coronary artery disease ${ }^{1}$ and total arterial myocardial revascularization is

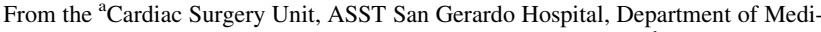
cine and Surgery, University of Milano-Bicocca, Monza, Italy; ${ }^{\mathrm{b}}$ Division of Cardiac Surgery, Department of Critical Care Medicine, Mazankowski Alberta Heart Institute, University of Alberta, Edmonton, Alberta, Canada; ${ }^{c}$ Emergency Department, IRCCS Humanitas Hospital, Milan, Italy; and ${ }^{\mathrm{d}}$ Statistics and Quality Health Service, ASST San Gerardo Hospital, Monza, Italy.

This study was funded by the University of Milano-Bicocca Fund for Research; Fondi di Ateneo per la Ricerca, F.A.R., grant number: 2017-ATE-0613.
}

advocated for patients younger than 60 years old ${ }^{2}$ or in patients with reasonable life expectancy of at least 15 to 20 years. $^{1,3}$ Multiple arterial grafts improve long-term

Received for publication July 6, 2018; revisions received Dec 16, 2018; accepted for publication Dec 26, 2018; available ahead of print Feb 10, 2019.

Address for reprints: Francesco Formica, MD, Clinica Cardiochirurgica, Ospedale San Gerardo, ASST Monza, Via G.B. Pergolesi 33, 20052 Monza (MB), Italy (E-mail: francesco formica@fastwebnet.it).

$0022-5223 / \$ 36.00$

Copyright (c) 2019 by The American Association for Thoracic Surgery

https://doi.org/10.1016/j.jtcvs.2018.12.078 


$$
\begin{aligned}
& \text { Abbreviations and Acronyms } \\
& \text { BIMA }=\text { bilateral internal mammary arteries } \\
& \text { CABG }=\text { coronary artery bypass grafting } \\
& \text { CI }=\text { confidence interval } \\
& \text { CPB }=\text { cardiopulmonary bypass } \\
& \text { CxA }=\text { circumflex coronary arteries } \\
& \text { ECMO }=\text { extracorporeal membrane oxygenation } \\
& \text { HR }=\text { hazard ratio } \\
& \text { IABP }=\text { intra-aortic balloon pump } \\
& \text { IQR }=\text { interquartile range } \\
& \text { PS }=\text { propensity score } \\
& \text { RA }=\text { radial artery } \\
& \text { RCA }=\text { right coronary artery } \\
& \text { SMD }=\text { standardized mean difference } \\
& \text { SV }=\text { saphenous vein }
\end{aligned}
$$

Scanning this $Q R$ code will take you to the article title page to access supplementary information.

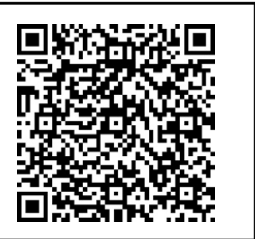

survival compared with single left internal mammary artery grafting or percutaneous coronary intervention. ${ }^{4,5}$ Radial artery (RA) $)^{6,7}$ or gastroepiploic artery, ${ }^{8-10}$ in addition to bilateral internal mammary arteries (BIMA), have been reported as conduits alternative to saphenous vein (SV) to effect complete myocardial revascularization. Several meta-analysis and review articles $^{11-14}$ described the RA as the third-most commonly used arterial conduit in addition to BIMA in patients who underwent $\mathrm{CABG}$. Preference for the RA over the right gastroepiploic artery is because of the relative technical ease of harvesting. Recent guidelines consider the use of the RA conduit reasonable when grafting the right coronary artery (RCA) with critical stenosis $(\geq 90 \%)$ or circumflex coronary arteries (CxA) with severe stenosis $(\geq 70 \%)^{2,15}$ These anatomical restrictions likely account for the lack of RA conduit adoption, and the historically low number of patients analyzed in various published studies. Moreover, recent randomized trials have reported conflicting midterm angiographic results of RA compared with SV graft. ${ }^{16-18}$

Whether full arterial revascularization with the RA used in addition to BIMA for 3-vessel coronary disease is associated with better midterm and long-term survival compared with SV used in addition to BIMA has not been clearly defined. In this study, we sought to evaluate the early and the long-term survival in patients with 3-vessel coronary disease who underwent CABG either with BIMA and the RA, or BIMA and the SV, to verify the effect of the RA as a third arterial conduit.

\section{METHODS}

The local ethical committee approved the Bilateral Internal Mammary Artery Plus RA-Long-Term Survival Analysis (BIMARS) study (approval: deliberation 836, June 8, 2017). Individual patient consent was waived. We retrospectively analyzed prospectively collected clinical data from the surgical registry at the San Gerardo Hospital, University of Milano-Bicocca (Monza, Italy) between June, 1999 and November, 2017. Of the 3750 patients who underwent isolated CABG during the study period, 2129 patients received at least 3 distal anastomoses. Among them, $660(31 \%)$ received BIMA in addition to either RA $(n=206)$ or SV $(n=454)$ grafting. Figure 1 shows a Consolidated Standards of Reporting Trials diagram illustrating the patient selection algorithm.

To be included, all subjects had at least 3-vessel coronary artery disease with 3 or more distal grafts performed. Patients with concomitant SV and RA $(\mathrm{n}=65)$ grafting or with concomitant SV on diagonal branch $(n=10)$ were excluded from the analysis.

In our series, the RA was used to graft the RCA with a critical stenosis $(\geq 90 \%)$ or the CxA with a severe stenosis $(\geq 70 \%)$. The RA was used as a " $Y$ " free graft connected to the left internal mammary artery or anastomosed to the ascending aorta. The right internal mammary artery was used either as pedicle graft or as " $\mathrm{Y}$ " fashion free graft from the left internal mammary artery.

\section{Terms, Data Collection, and Study End Points}

Early mortality, or procedural mortality, was defined as any death within 30 days of CABG, whether occurring during hospitalization, or after discharge. Late death was defined as death occurring after 30 days from surgery. Follow-up information was obtained from the Local Regional Institutional Health Database System. All-cause mortality was used to assess long-term outcome. All-cause mortality is the most robust and unbiased index because subjective or biased clinical documentation/assessment is avoided. ${ }^{19}$

The following preoperative variables were included in the model: gender, age, surgical era (1999-2008 and 2009-2017), diabetes mellitus (oral or insulin therapy), smoking history (previous or current), dyslipidaemia, chronic obstructive pulmonary disease, previous cerebrovascular events (transient ischemic attack or stroke), paroxysmal and permanent atrial fibrillation, redo surgery, body mass index, creatinine, New York Heart Association functional class, Canadian Cardiovascular Society functional class, peripheral vascular disease, carotid artery disease, chronic congestive heart failure, unstable angina, recent myocardial infarction (within 90 days), left main disease $(>50 \%)$, left ventricle ejection fraction, percutaneous coronary intervention, timing of surgery (urgent or emergent), European System for Cardiac Operative Risk Evaluation-II and Society of Thoracic Surgeons mortality score.

Perioperative and postoperative data collected included: aortic clamp time, cardiopulmonary bypass (CPB) time, number of distal grafts, mode of surgery (off-pump CABG, conventional CPB, or miniaturized $\mathrm{CPB}$ ), modality of $\mathrm{CPB}$ weaning (without inotropes, with inotropes, assisted with intra-aortic balloon pump [IABP] or assisted with extracorporeal membrane oxygenation [ECMO]), reoperation for bleeding, blood transfusion, new-onset cerebrovascular event, prolonged ventilation (>48 hours), acute kidney injury, need for renal therapy replacement, creatinine peak, perioperative myocardial infarction, creatine-kinase myocardial band peak, pneumonia, inotrope requirement, need for IABP, duration of IABP, low cardiac output, need for ECMO, duration of ECMO, deep sternal wound infection (wound infection without sternal split, mediastinitis, sternal split without infection), and new-onset atrial fibrillation. 

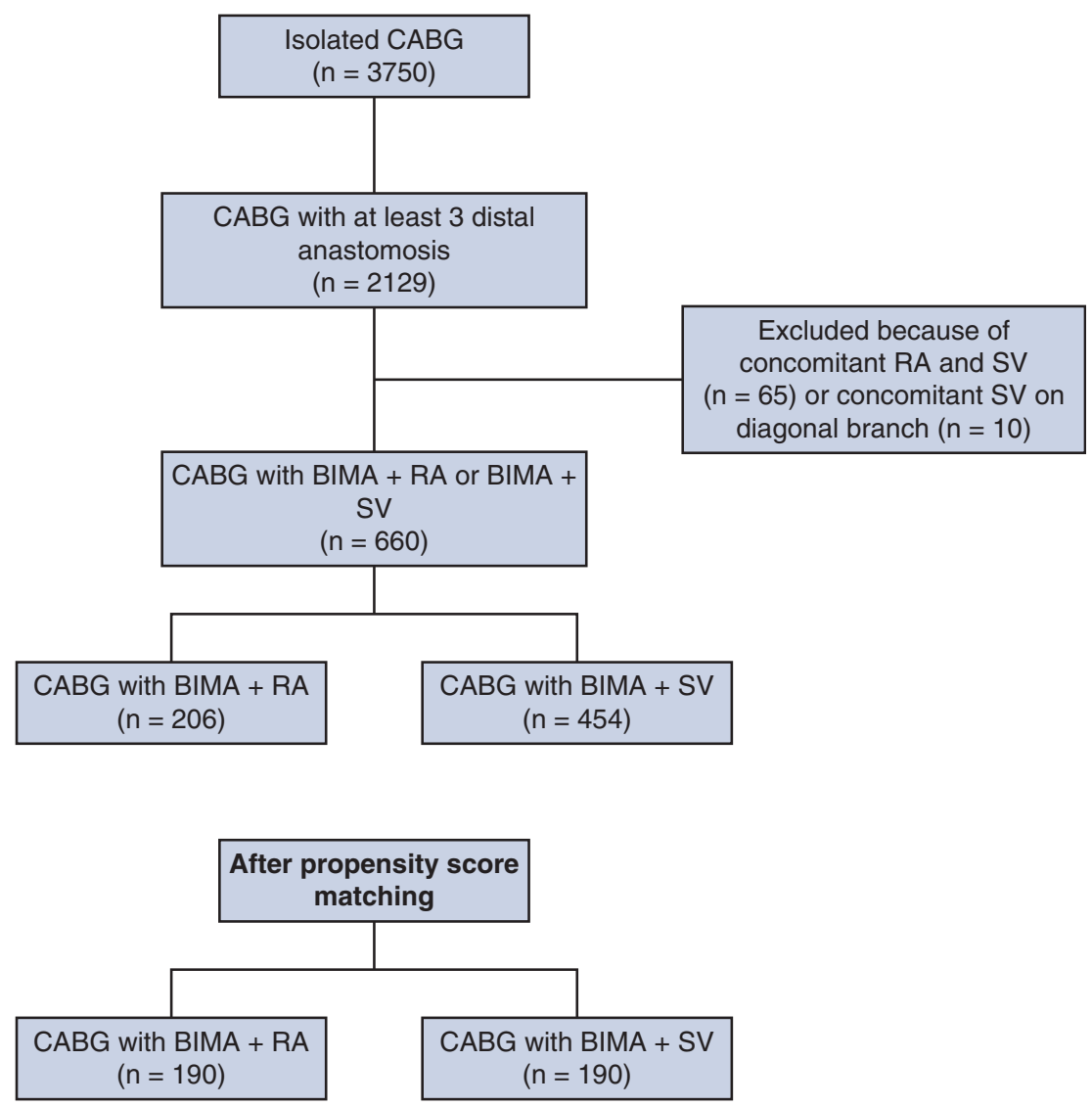

FIGURE 1. Consolidated Standards of Reporting Trials diagram of study population. $C A B G$, coronary artery bypass grafting; $R A$, radial artery; $B I M A+R A$, Bilateral internal mammary arteries and additional use of radial artery; $B I M A+S V$, bilateral internal mammary arteries and additional use of saphenous vein.

\section{Statistical Analysis}

Descriptive statistics for categorical variables are reported as frequency and percentage; continuous variables are reported as mean \pm standard deviation.

A propensity score (PS) was generated for each patient from a multivariable logistic regression model to reduce the effect of potential confounding pretreatment variables. A multivariable logistic regression model was generated with treatment type as a dependent variable. The resulting PS for each patient represented the probability of being in the BIMA + RA or BIMA + SV group. The goodness of fit of the method was evaluated using the Hosmer-Lemeshow test $(P=.76)$ and the model achieved good discriminative power with a receiver operating curve resulting in an area under the curve of 0.75 (95\% confidence interval [CI], 0.68-0.83).

Two pairs of matched patients (BIMA + RA or BIMA + SV) were obtained using the greedy-matching algorithm to implement nearest-neighbor $1: 1$, with a caliper width of 0.2 standard deviation of the logit of the PS, without replacement. ${ }^{20}$ Pretreatment variables selected in the PSmatched patients were compared using the standardized mean difference (SMD) to assess the quality of the matching. The SMD represents the difference in mean between the 2 groups in units of standard deviation. A rule of thumb suggests a meaningful covariate balance between the 2 groups when the SMD is $<10 \%{ }^{21,22}$ To measure the treatment effect in the matched population, the Wilcoxon signed rank test was used for continuous data, whereas the McNemar test with odds ratios and $95 \%$ CI was used to compare categorical postoperative outcome. Overall survival was estimated using the Kaplan-Meier method and was expressed as percentage. The Kaplan-Meier method was used to draw survival curves and calculate 5-, 10-, and 15-year survival statistics. The stratified log rank test was applied to compare the equality of the survival curves in the matched population. ${ }^{22,23}$ Long term outcome was all-cause mortality.

We used the Cox regression model stratified on the matched pairs to estimate the unadjusted and adjusted hazard ratio (HR) and 95\% CI of longterm mortality during follow-up between the 2 groups. We also applied the Cox regression model to regress the outcome on 2 variables, the treatment and the estimated PS. ${ }^{6}$

A 2 -tailed $P$ value $<.05$ was always considered to indicate statistical significance. All statistical analysis was performed using IBM SPSS Statistics for Windows, version 25.0 (IBM Corp, Armonk, NY) and Stata/MP 15.1 (StataCorp, College Station, Tex).

\section{RESULTS}

After PS matching, 2 groups of 190 subjects were obtained. Preoperative variables before and after matching are presented in Table 1. Before matching, patients in group BIMA + RA were older, had fewer men, were more frequently diabetic (oral medication), more often presented with chronic congestive heart failure, had a higher Society of Thoracic Surgeons mortality score, and fewer distal anastomosis. After matching, the 2 groups were comparable for all preoperative variables (Figure 2). 
TABLE 1. Baseline covariate distribution between bilateral internal mammary arteries with use of radial artery and bilateral internal mammary arteries and use of saphenous vein in the unmatched and matched population

\begin{tabular}{|c|c|c|c|c|c|c|c|c|}
\hline \multirow[b]{2}{*}{ Variable } & \multicolumn{4}{|c|}{$\begin{array}{r}\text { Unmatched population } \\
\end{array}$} & \multicolumn{4}{|c|}{ Matched population } \\
\hline & $\begin{array}{c}\overline{\text { BIMA + RA }} \\
(\mathbf{n}=206)\end{array}$ & $\begin{array}{c}\text { BIMA + SV } \\
(n=454)\end{array}$ & SMD & $P$ value & $\begin{array}{c}\overline{\text { BIMA + RA }} \\
(\mathbf{n}=\mathbf{1 9 0})\end{array}$ & $\begin{array}{c}\text { BIMA + SV } \\
(\mathbf{n}=190)\end{array}$ & SMD & $P$ value \\
\hline Propensity score & $0.38 \pm 0.17$ & $0.27 \pm 0.12$ & 0.629 & $<.0001$ & $0.35 \pm 0.14$ & $0.35 \pm 0.13$ & 0.039 & .62 \\
\hline Male sex & $174(84.5)$ & $425(93.6)$ & -0.252 & $<.0001$ & $165(86.8)$ & $167(87.9)$ & -0.029 & .75 \\
\hline Age, y & $61.4 \pm 8.9$ & $59.6 \pm 6.7$ & 0.195 & .01 & $60.7 \pm 6.7$ & $59.5 \pm 6.4$ & 0.085 & .13 \\
\hline Era of surgery (1999-2008) & $105(51)$ & $234(51.5)$ & 0.009 & .89 & $100(52.6)$ & $105(55.3)$ & -0.050 & .60 \\
\hline Era of surgery (2009-2017) & $101(49)$ & $220(48.5)$ & 0.011 & .87 & $90(47.4)$ & $85(44.7)$ & 0.053 & .62 \\
\hline NIDDM & $47(22.8)$ & $67(14.8)$ & 0.192 & .01 & $38(20)$ & $31(16.3)$ & 0.088 & .35 \\
\hline IDDM & $3(1.5)$ & $10(2.2)$ & -0.062 & .52 & $3(1.6)$ & $3(1.6)$ & 0 & $>.99$ \\
\hline Hypertension & $177(85.9)$ & 375 (82.6) & 0.095 & .28 & $163(85.8)$ & $161(84.7)$ & 0.03 & .77 \\
\hline Ex-smoker & $58(28.2)$ & 145 (31.9) & -0.084 & .14 & $52(27.4)$ & $55(28.9)$ & -0.035 & .94 \\
\hline Current smoker & $37(18)$ & $56(12.5)$ & 0.146 & .15 & $33(8.7)$ & $32(8.4)$ & 0.014 & .93 \\
\hline Dyslipidemia & $149(72.3)$ & $305(67.2)$ & 0.115 & .18 & 136 (71.6) & $137(72.1)$ & -0.012 & .90 \\
\hline COPD & $13(6.3)$ & $27(5.9)$ & 0.015 & .85 & $9(4.7)$ & $6(3.2)$ & 0.065 & .42 \\
\hline Previous TIA & $8(3.9)$ & $16(3.5)$ & 0.019 & .97 & $4(2.1)$ & $5(2.6)$ & -0.027 & .94 \\
\hline Previous stroke & $1(0.5)$ & $2(0.4)$ & 0.006 & .97 & $1(0.5)$ & $1(0.5)$ & 0 & $>.99$ \\
\hline PAF & $9(4.4)$ & $10(2.2)$ & 0.106 & .25 & $6(3.2)$ & $7(3.7)$ & -0.026 & .77 \\
\hline Permanent AF & $1(0.5)$ & $1(0.2)$ & 0.038 & .25 & $0(0)$ & $0(0)$ & 0 & - \\
\hline Redo surgery & $2(1)$ & $2(0.4)$ & 0.054 & .41 & $1(0.5)$ & $2(1.1)$ & -0.054 & .56 \\
\hline BMI & $26.5 \pm 3.4$ & $26.2 \pm$ & 0.088 & .29 & $26.5 \pm 3.2$ & $26.5 \pm 3.7$ & -0.031 & .76 \\
\hline Creatinine, $\mathrm{mg} / \mathrm{dL}$ & $0.95 \pm 0.25$ & $0.97 \pm 0.23$ & -0.09 & .27 & $0.94 \pm 0.23$ & $0.96 \pm 0.23$ & -0.062 & .51 \\
\hline NYHA class & $1.3 \pm 0.5$ & $1.3 \pm 0.49$ & 0.018 & .82 & $1.29 \pm 0.54$ & $1.26 \pm 0.48$ & 0.047 & .61 \\
\hline CCS class & $2.3 \pm 0.8$ & $2.5 \pm 0.8$ & -0.195 & .02 & $2.34 \pm 0.81$ & $2.37 \pm 0.88$ & -0.038 & .71 \\
\hline Peripheral arteriopathy & $19(9.2)$ & $27(5.9)$ & 0.113 & .12 & $12(6.3)$ & $14(7.4)$ & -0.036 & .68 \\
\hline Carotid disease & $24(11.7)$ & $35(7.7)$ & 0.123 & .10 & $17(8.9)$ & $14(7.4)$ & 0.049 & .68 \\
\hline Chronic congestive heart failure & $13(6.3)$ & $11(2.4)$ & 0.16 & .01 & $7(3.7)$ & $8(4.2)$ & -0.022 & .79 \\
\hline Unstable angina & $26(12.6)$ & $94(20.7)$ & -0.243 & .01 & $24(12.6)$ & $26(13.7)$ & -0.032 & .76 \\
\hline Recent MI & $50(24.3)$ & $144(31.7)$ & -0.173 & .05 & $45(23.7)$ & $44(23.2)$ & 0.012 & .90 \\
\hline Left main disease & $54(26.2)$ & $124(27.3)$ & -0.025 & .76 & $51(26.8)$ & $51(26.8)$ & 0 & $>.99$ \\
\hline LV EF, \% & $55.3 \pm 8.8$ & $56.5 \pm 7.4$ & -0.135 & .09 & $55.9 \pm 8.3$ & $56.5 \pm 8$ & -0.06 & .53 \\
\hline Previous PCI & $16(7.8)$ & $46(10.1)$ & -0.088 & .33 & $13(6.8)$ & $11(5.8)$ & 0.039 & .67 \\
\hline Urgent surgery & $12(5.8)$ & $29(6.4)$ & -0.024 & .78 & $11(5.8)$ & $9(4.7)$ & 0.045 & .64 \\
\hline EuroSCORE II & $0.91 \pm 0.52$ & $0.83 \pm 0.72$ & 0.111 & .23 & $0.87 \pm 0.53$ & $0.8 \pm 0.6$ & 0.09 & .86 \\
\hline STS score mortality & $0.71 \pm 0.83$ & $0.54 \pm 0.63$ & 0.258 & .001 & $0.63 \pm 0.49$ & $0.61 \pm 0.83$ & 0.02 & .81 \\
\hline Distal anastomosis & $3.08 \pm 0.27$ & $3.2 \pm 0.48$ & -0.435 & $<.0001$ & $3.09 \pm 0.28$ & $3.11 \pm 0.33$ & -0.076 & .50 \\
\hline
\end{tabular}

Categorical variables are reported as frequency and percentage; continuous variables are reported as mean \pm standard deviation. BIMA $+R A$, Bilateral internal mammary arteries and additional use of radial artery; $B I M A+S V$, bilateral internal mammary arteries and additional use of saphenous vein; SMD, standardized mean difference; $N I D D M$, noninsulin-dependent diabetes; IDDM, insulin-dependent diabetes; $C O P D$, chronic obstructive pulmonary disease; TIA, transitory ischemic attack; PAF, parossistical atrial fibrillation; $A F$, atrial fibrillation; $B M I$, body mass index; $N Y H A$, New York Heart Association; $C C S$, Canadian Cardiovascular Society; $M I$, myocardial infarction; $L V$, left ventricle; $E F$, ejection fraction; PCI, percutaneous coronary intervention; EuroSCORE, European System for Cardiac Operative Risk Evaluation; STS, Society of Thoracic Surgery.

\section{Perioperative Data}

Off-pump CABG was more common in the BIMA + RA group. The number of distal anastomoses was significantly higher in BIMA + SV subjects (Table 2). Graft target distribution is summarized in Table 3. RA was anastomosed to the RCA in 160 patients $(84.2 \%)$ and to the CxA in 30
$(15.8 \%)$. In the BIMA + SV group, the RCA was grafted in 183 patients $(93.7 \%)$ and $\mathrm{CxA}$ in $7(3.6 \%)$. RA was used as "Y" free graft in 16 patients $(8.4 \%)$. The right internal mammary artery was used as " $Y$ " free graft in 21 patients $(11 \%)$ in the BIMA + RA group and in 26 patients $(13.7 \%)$ in the BIMA + SV group (Video 1). 


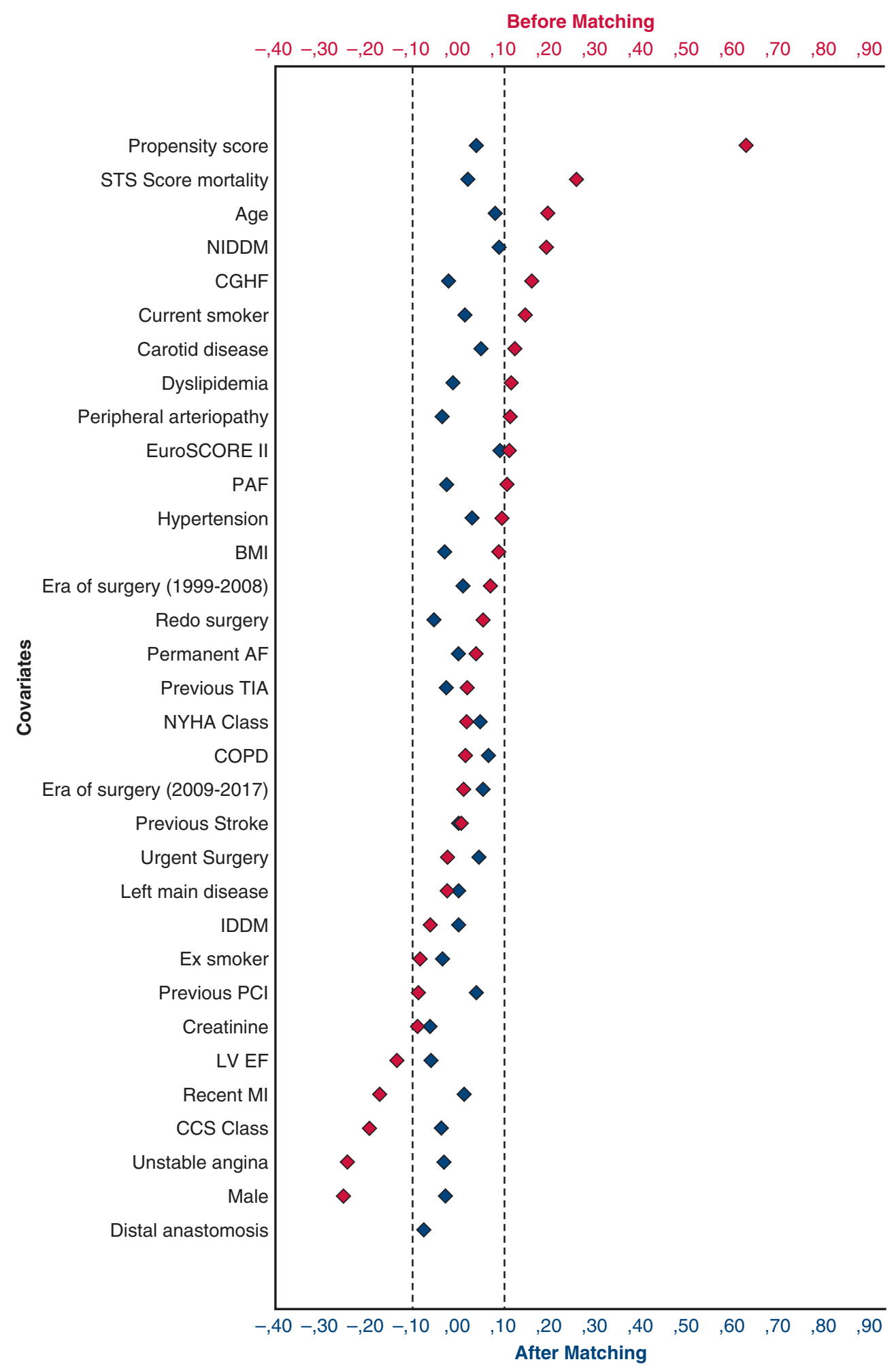

FIGURE 2. Covariance balance plot (Love plot) before and after propensity matching for patients who underwent CABG with BIMA + RA or BIMA + SV. STS, Society of Thoracic Surgeons; NIDDM, non-insulin-dependent diabetes; $C G H F$, chronic congestive heart failure; EuroSCORE, European System for Cardiac Operative Risk Evaluation; $P A F$, parossistical atrial fibrillation; $B M I$, body mass index; $A F$, atrial fibrillation; TIA, transitory ischemic attack; NYHA, New York Heart Association; COPD, chronic obstructive pulmonary disease; IDDM, insulin-dependent diabetes; PCI, percutaneous coronary intervention; $L V E F$, left ventricle ejection fraction; $M I$, myocardial infarction; $C C S$, Canadian Cardiovascular Society. 
TABLE 2. Intraoperative data in the matched population

\begin{tabular}{lccc}
\hline \multicolumn{1}{c}{ Variable } & $\begin{array}{c}\text { BIMA }+ \text { RA } \\
(\mathbf{n}=\mathbf{1 9 0})\end{array}$ & $\begin{array}{c}\text { BIMA }+ \text { SV } \\
(\mathbf{n}=\mathbf{1 9 0})\end{array}$ & $\boldsymbol{P}$ value \\
\hline Mean aortic clamp time & $75.4 \pm 20.6$ & $75.9 \pm 18.9$ & .82 \\
Mean CPB time & $97.4 \pm 23.9$ & $99.9 \pm 24.6$ & .33 \\
Mean anastomosis & $3.09 \pm 0.28$ & $3.11 \pm 0.33$ & .50 \\
OPCABG, n $(\%)$ & $18(9.5)$ & $2(1.1)$ & $<.0001$ \\
Conventional CPB, n $(\%)$ & $160(84.2)$ & $178(93.7)$ & .31 \\
Miniaturized CPB, n $(\%)$ & $12(6.3)$ & $10(5.3)$ & .72 \\
Weaning off CPB & $172 / 190$ & $188 / 190$ & .42 \\
Without inotropes, n $(\%)$ & $172(100)$ & $185(98.5)$ & \\
With inotropes, n $(\%)$ & $0(0)$ & $1(0.5)$ & \\
IABP, n $(\%)$ & $0(0)$ & $1(0.5)$ & \\
ECMO, n $(\%)$ & 0 & $1(0.5)$ & \\
\hline
\end{tabular}

$\overline{B I M A}+R A$, Bilateral internal mammary arteries and additional use of radial artery; $B I M A+S V$, bilateral internal mammary arteries and additional use of saphenous vein; $C P B$, cardiopulmonary bypass; $O P C A B G$, off-pump coronary artery bypass grafting; $I A B P$, intra-aortic balloon pump; ECMO, extracorporeal membrane oxygenation.

\section{Early Outcomes}

In the unmatched patients, 30-day mortality occurred in 5 patients $(0.7 \%)$ with 3 deaths $(1.4 \%)$ observed in the BIMA + RA group and 2 deaths $(0.4 \%)$ in the BIMA + SV group. In the matched subjects, 30-day mortality occurred in 4 patients $(01 \%)$, with 2 deaths $(1.1 \%)$ in the BIMA + RA group and 2 deaths $(1.1 \%)$ in BIMA + SV group $(P>.99)$. After matching, there were not any significant differences between the 2 groups regarding the other postoperative variables analyzed. Postoperative outcomes

TABLE 3. Grafted distribution in the BIMA + RA and BIMA + SV group in the matched population

\begin{tabular}{lcc}
\hline \multicolumn{1}{c}{ Variable } & $\begin{array}{c}\text { BIMA }+ \text { RA } \\
(\mathbf{n}=\mathbf{1 9 0})\end{array}$ & $\begin{array}{c}\text { BIMA }+ \text { SV } \\
(\mathbf{n}=\mathbf{1 9 0})\end{array}$ \\
\hline LIMA on LAD, n (\%) & $190(100)$ & $183(96.3)$ \\
RIMA on: & & $7(3.7)$ \\
LAD, n (\%) & $0(0)$ & $176(92.6)$ \\
CX, n $(\%)$ & $160(84.2)$ & $7(3.7)$ \\
RCA, n $(\%)$ & $30(15.8)$ & - \\
RA on: & & - \\
CX, n $(\%)$ & $30(15.8)$ & $7(3.6)$ \\
RCA, n $(\%)$ & $160(84.2)$ & $183(93.7)$ \\
SV on: & - & - \\
CX, n $(\%)$ & - & $26(13.7)$ \\
RCA, n $(\%)$ & $16(8.4)$ & \\
RA free graft, n $(\%)$ & $21(11)$ & \\
RIMA free graft, n $(\%)$ & & \\
\hline
\end{tabular}

$B I M A+R A$, Bilateral internal mammary arteries and additional use of radial artery; $B I M A+S V$, bilateral internal mammary arteries and additional use of saphenous vein; LIMA, left internal mammary artery; LAD, left anterior descending artery; RIMA, right internal mammary artery; $C X$, circumflex coronary artery; $R C A$, right coronary artery; $R A$, radial artery; $S V$, saphenous vein.

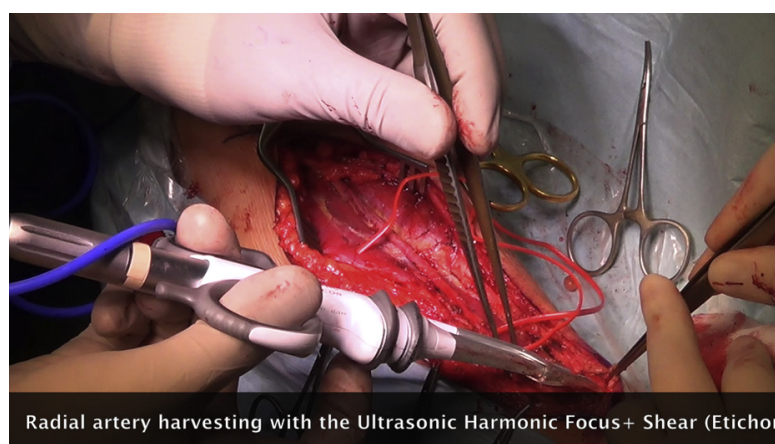

VIDEO 1. Total arterial myocardial revascularization operation in a 71-year-old patient using bilateral internal mammary arteries and radial artery. A Y-shape graft was constructed between the right internal mammary artery (free graft) and the left internal mammary artery. The right internal mammary artery was used to revascularize the first and second obtuse marginal branches with sequential anastomosis; the left internal mammary artery was used to graft the left anterior descending artery; finally, the radial artery was applied to graft the posterior descending artery. The operation was performed using cardiopulmonary bypass and cross aortic clamping. Video available at: https://www.jtcvs.org/article/S00225223(19)30005-4/fulltext.

of the unmatched and matched populations are reported in Table 4.

\section{Long-Term Outcomes}

In the unmatched patients, survival at 5,10 , and 15 years were $93.1 \pm 1.9 \%, 82 \pm 3.1 \%$, and $75.1 \pm 4.2 \%$ in the BIMA + RA group and $97.2 \pm 0.8 \%, 86.4 \pm 1.9 \%$, and $80.7 \pm 2.5 \%$ in the BIMA $+\mathrm{SV}$ group (log rank $P=.10$; Figure $3, A$ ). In the matched groups, the overall median follow-up time was 9.2 years (interquartile range [IQR], 5.6-13 years) with a maximum follow-up time of 18.5 years. The estimated mean time until death was $15.6 \pm 0.3$ years $(95 \%$ CI, 15.06-16.24). The median follow-up time was 9.2 (IQR, 5.6-11.9) years in the BIMA + RA patients and 9.3 (IQR, 5.5-14.4) years in the BIMA + SV patients. Survival at 5, 10, and 15 years were $94.8 \pm 1.7 \%, 83.7 \pm 3.1 \%$, and $78.6 \pm 3.9 \%$ in the BIMA + RA group and $96.2 \pm 1.4 \%, 85.1 \pm 2.9 \%$, and $80.4 \pm 3.6 \%$ in the BIMA $+\mathrm{SV}$ group (stratified log rank $P=.78$; Figure $3, B$ ). Late death among the matched population was modeled using Cox regression analysis. The 15-year unadjusted HR showed that the use of RA did not affect late mortality (HR, 1.07; 95\% CI, 0.63-1.82; $P=.78)$. The PS adjusted HR showed that the use of the RA was not associated with late mortality (adjusted HR, $1.05 ; 95 \%$ CI, 0.62-1.79; $P=.83$ ) (Figure 4).

\section{DISCUSSION}

The major finding of this study was that in a matched population who underwent isolated CABG with BIMA 
TABLE 4. Postoperative data of unmatched and matched population

\begin{tabular}{|c|c|c|c|c|c|c|c|c|}
\hline \multirow[b]{2}{*}{ Variable } & \multicolumn{4}{|c|}{ Unmatched population } & \multicolumn{4}{|c|}{ Matched population } \\
\hline & $\begin{array}{c}\overline{\text { BIMA + RA }} \\
(\mathbf{n}=\mathbf{2 0 6})\end{array}$ & $\begin{array}{c}\text { BIMA + SV } \\
(n=454)\end{array}$ & $P$ value & $\begin{array}{c}\text { OR } \\
(95 \% \mathrm{CI})\end{array}$ & $\begin{array}{c}\overline{\text { BIMA + RA }} \\
(\mathbf{n}=\mathbf{1 9 0})\end{array}$ & $\begin{array}{c}\text { BIMA + SV } \\
(\mathbf{n}=\mathbf{1 9 0})\end{array}$ & $P$ value & $\begin{array}{c}\text { OR } \\
(95 \% \text { CI })^{*}\end{array}$ \\
\hline $\begin{array}{l}\text { Reoperation for bleeding, } \mathrm{n} \\
\quad(\%)\end{array}$ & $4(1.9)$ & $10(2.2)$ & .82 & $0.87(0.27-2.83)$ & $4(2.1)$ & $2(1.1)$ & .41 & $2.02(0.36-11.47)$ \\
\hline Blood transfusion, $\mathrm{n}(\%)$ & $73(35.4)$ & $129(28.4)$ & .07 & $1.38(0.97-1.96)$ & $68(35.8)$ & $58(30.5)$ & .27 & $1.12(0.82-1.94)$ \\
\hline Stroke, n (\%) & $0(0)$ & $3(0.6)$ & .28 & - & $0(0)$ & $2(1.1)$ & .15 & - \\
\hline $\begin{array}{l}\text { Prolonged ventilation }(>48 \mathrm{~h}) \text {, } \\
\quad \mathrm{n}(\%)\end{array}$ & $24(11.7)$ & $57(12.6)$ & .74 & $0.91(0.55-1.52)$ & $23(12.1)$ & $23(12.1)$ & $>.99$ & $1(0.54-1.85)$ \\
\hline Pneumonia, n (\%) & $5(2.4)$ & $15(3.3)$ & .54 & $0.72(0.26-2.03)$ & $5(2.6)$ & $7(3.7)$ & .55 & $0.70(0.22-2.26)$ \\
\hline Acute kidney injury, n (\%) & $0(0)$ & $1(0.2)$ & .50 & - & $0(0)$ & $0(0)$ & - & - \\
\hline Mean creatinine peak, $\mathrm{mg} / \mathrm{dL}$ & $0.90 \pm 0.22$ & $0.93 \pm 0.21$ & .11 & - & $0.89 \pm 0.22$ & $0.91 \pm 0.24$ & .40 & - \\
\hline $\mathrm{AF}, \mathrm{n}(\%)$ & $48(23.3)$ & $94(20.7)$ & .45 & $1.16(0.78-1.72)$ & $40(21.1)$ & $41(21.6)$ & .90 & $0.96(0.59-1.58)$ \\
\hline Discharged with AF, n (\%) & $5 / 48(10.4)$ & $5 / 94(5.6)$ & & & $1 / 40(2.5)$ & $2 / 41(5.1)$ & & \\
\hline SR after amiodarone, $\mathrm{n}(\%)$ & $38 / 48(79.2)$ & 78/94 (86.7) & & & $35 / 40(87.5)$ & $35 / 41(89.7)$ & & \\
\hline $\begin{array}{l}\text { SR after electrical } \\
\quad \text { cardioversion, } \mathrm{n}(\%)\end{array}$ & $3 / 48(6.3)$ & $4 / 94$ & & & $2 / 40(5)$ & $1 / 41(2.6)$ & & \\
\hline $\begin{array}{l}\text { Spontaneous cardioversion, } \mathrm{n} \\
\quad(\%)\end{array}$ & $2 / 48(4.2)$ & $3 / 94(3.3)$ & & & $2 / 40(5)$ & $1 / 41(2.6)$ & & \\
\hline Perioperative MI, n (\%) & $6(2.9)$ & $16(3.5)$ & .68 & $0.82(0.31-2.13)$ & $6(3.2)$ & $7(3.7)$ & .77 & $0.85(0.28-2.58)$ \\
\hline CK-MB & $23.9 \pm 51.9$ & $27.1 \pm 54.6$ & .48 & - & $24.4 \pm 54$ & $29.9 \pm 70.3$ & .39 & - \\
\hline Inotropes, $\mathrm{n}(\%)$ & $63(30.6)$ & $136(30)$ & .87 & $1.03(0.72-1.47)$ & $55(28.9)$ & $61(32.1)$ & .50 & $0.86(0.55-1.33)$ \\
\hline Low cardiac output, n (\%) & $1(0.5)$ & $4(0.9)$ & .58 & $0.54(0.06-4.94)$ & $1(0.5)$ & $1(0.5)$ & $>.99$ & $1(0.06-16.10)$ \\
\hline Postoperative IABP, n (\%) & $5(2.4)$ & $22(4.8)$ & .14 & $0.48(0.18-1.30)$ & $5(2.6)$ & $8(4.2)$ & .39 & $0.61(0.19-1.91)$ \\
\hline ECMO, n $(\%)$ & $0(0)$ & $3(0.7)$ & .24 & - & $0(0)$ & $2(1.1)$ & .15 & - \\
\hline ECMO time (d) & - & $2(1.4)$ & - & - & - & $2(1.4)$ & - & - \\
\hline MOF, n (\%) & $3(1.5)$ & $2(0.4)$ & .16 & $3.34(0.55-20.14)$ & $2(1.1)$ & $1(0.5)$ & .56 & $2.01(0.18-22.36)$ \\
\hline DSW infection, $\mathrm{n}(\%)$ & $6(2.9)$ & $10(2.2)$ & .58 & $1.33(0.47-3.71)$ & $6(3.2)$ & $4(2.1)$ & .52 & $1.51(0.42-5.46)$ \\
\hline Wound infection & $4(1.9)$ & $8(1.8)$ & & & $4(2.1)$ & $3(1.6)$ & & \\
\hline Mediastinitis & $1(0.5)$ & $0(0)$ & & & $1(0.5)$ & $0(0)$ & & \\
\hline Sternal split without infection & $1(0.5)$ & $2(0.4)$ & & & $1(0.5)$ & $1(0.5)$ & & \\
\hline Mean IABP duration, d & $2.2 \pm 1.6$ & $2 \pm 0.5$ & .84 & - & $2.2 \pm 1.6$ & $1.7 \pm 0.7$ & .58 & - \\
\hline Mean ICU length of stay, $d$ & $1.2 \pm 0.8$ & $1.3 \pm 1.1$ & .39 & - & $1.2 \pm 0.7$ & $1.2 \pm 0.8$ & .66 & - \\
\hline Mean hospital length of stay, $d$ & $6.3 \pm 3.3$ & $6.6 \pm 5.7$ & .39 & - & $6.2 \pm 3.1$ & $6.2 \pm 3.9$ & .92 & - \\
\hline 30-d mortality, n (\%) & $3(1.4)$ & $2(0.4)$ & .16 & $3.34(0.55-20.14)$ & $2(1.1)$ & $2(1.1)$ & $>.99$ & $1.00(0.13-7.17)$ \\
\hline
\end{tabular}

$B I M A+R A$, Bilateral internal mammary arteries and additional use of radial artery; $B I M A+S V$, bilateral internal mammary arteries and additional use of saphenous vein; $O R$, odds ratio; $C I$, confidence interval; $A F$, atrial fibrillation; $S R$, sinus rhythm; $M I$, myocardial infarction; $C K$ - $M B$, creatine-kinase myocardial band; $I A B P$, intra-aortic balloon pump; $E C M O$, extracorporeal membrane oxygenation; $M O F$, multiorgan failure; $D S W$, deep sternal wound; $I C U$, intensive care unit. * McNemar test.

and the RA, the additional use of the RA as a third arterial conduit was associated with long-term survival comparable with that of patients who underwent CABG surgery with BIMA and the SV. Late survival was not statistically different between the 2 groups in the unadjusted and adjusted analyses. The clinical benefit of the RA for full arterial revascularization is recognized but widespread dissemination has lagged. In recent meta-analysis of 1036 patients, Gaudino and colleagues ${ }^{24}$ reported a lower incidence of cardiac events, repeat revascularization, myocardial infarction, death from any cause, and a higher rate of 5-year patency in RA graft compared with SV graft. The meta-analysis reported also data from randomized trials, such as the Radial Artery Versus Saphenous Vein Patency trial and the Radial Artery Patency Study trial, which have both reported superior angiographic graft patency of the RA compared with the SV at 5 years postoperatively, and angiographic results from the Radial Artery Patency and Clinical Outcome trial, for which no differences were found in terms of 5-year patency between the 


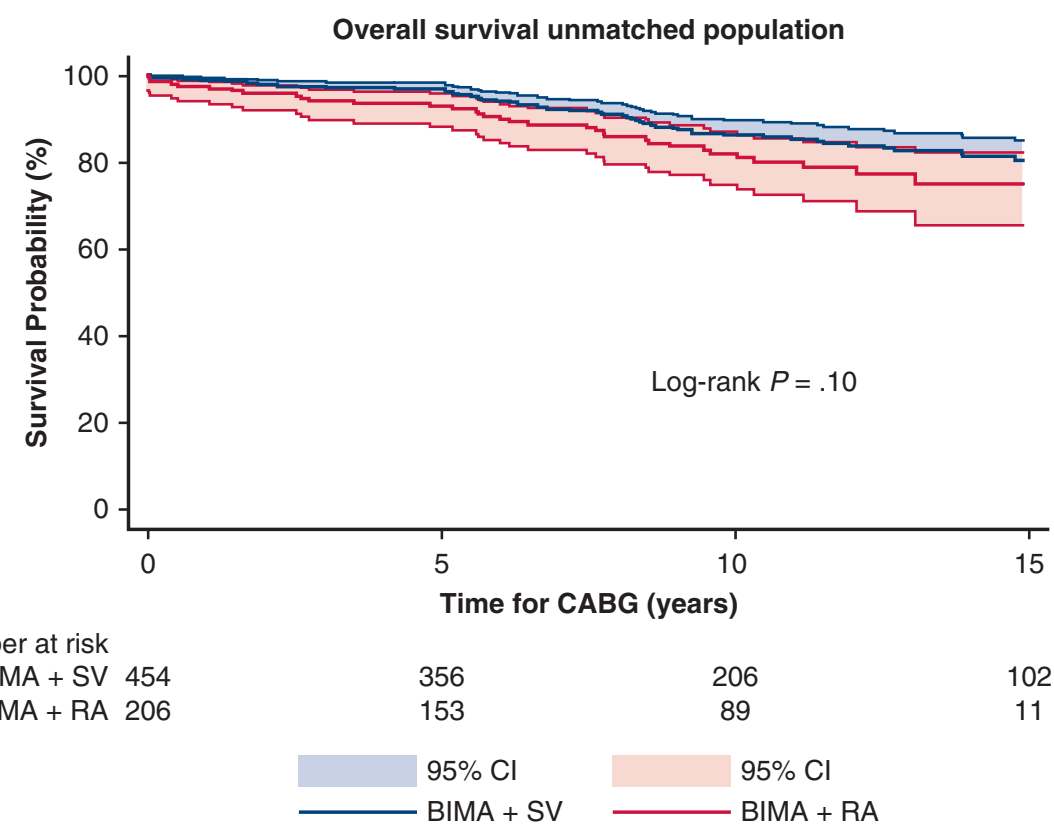

A

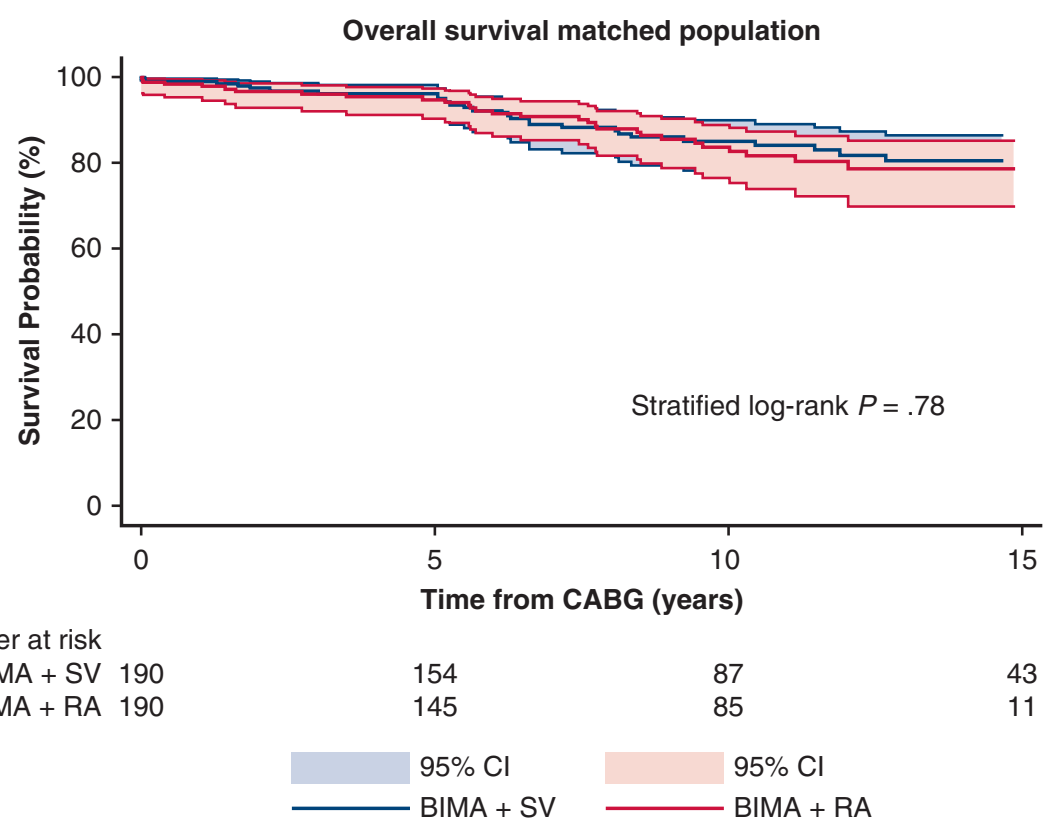

FIGURE 3. Comparison of survival probability in patients who underwent BIMA + RA versus BIMA + SV in unmatched population (A) and matched population (B). $C A B G$, Coronary artery bypass grafting; $B I M A+R A$, bilateral internal mammary arteries and additional use of radial artery; $B I M A+S V$, bilateral internal mammary arteries and additional use of saphenous vein; $C I$, confidence interval.

RA and the SV. These conflicting data might explain why the RA is still not widely accepted as an arterial conduit in CABG, although recent data from large retrospective studies $^{4,25,26}$ have shown that multiple arterial grafts improve late survival. Despite the observed benefits of BIMA grafting, routine use of this strategy is applied in only approximately $4 \%$ of coronary patients in Canada, ${ }^{27} 7 \%$ to $10 \%$ in the United States, ${ }^{14,28}$ and $12 \%$ in Europe. ${ }^{29}$ The observed lack of frequent multiple arterial conduit usage, despite clinical benefits reported in the literature, explains the conflicting data on comparisons of the RA or SV used in addition to BIMA in terms of longterm survival. In fact, to the best of our knowledge, most of the studies have analyzed relatively small groups of patients.

Because the operations for the patients in the study occurred over a period of 18 years, we considered it appropriate to divide the subjects into 2 eras (1999-2008 and 


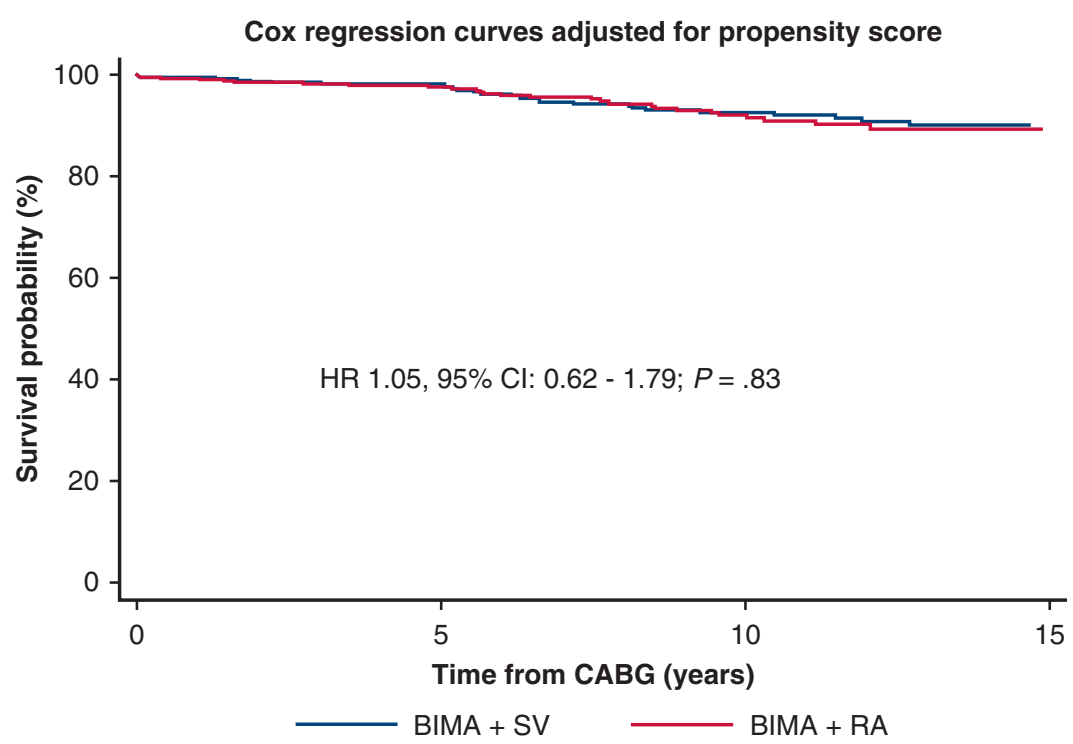

FIGURE 4. Survival probability, propensity score adjusted Cox regression analysis between BIMA + RA and BIMA + SV groups. $C A B G$, Coronary artery bypass grafting; $B I M A+S V$, bilateral internal mammary arteries and additional use of saphenous vein; $B I M A+R A$, bilateral internal mammary arteries and additional use of radial artery; $H R$, hazard ratio; $C I$, confidence interval.

2009-2017) to verify if any differences in patient selection, surgical techniques, surgeon's learning curve, and surgeon's preference could affect the results. No differences between the 2 eras were reported for early and late outcomes.

In this study, long-term survival between the 2 groups was comparable and our results are consistent with other recent reports. Di Mauro and colleagues ${ }^{30}$ published an 8 -year survival of $91.9 \pm 2.9 \%$ for patients who received BIMA + RA CABG compared with $95.6 \pm 0.9 \%$ for patients who received BIMA + SV CABG $(P=.12)$, without any observed differences between groups. The patients were not matched and the RA group $(n=87)$ was strongly unbalanced compared with the SV group $(\mathrm{n}=590)$.

Mohammadi and colleagues ${ }^{31}$ reported similar long-term results (median follow-up of 8 years) between BIMA + RA and BIMA + SV patients. In that study, in which 249 matched pairs of patients were analyzed, the investigators were unable to show any differences even when BIMA + RA patients were stratified according to the severity of the stenosis of the coronary target. The authors attributed the lack of long-term survival difference to small sample size, low burden of preoperative risk factors, and that all patients had received BIMA to graft the 2 most important myocardial territories.

Recently, Grau and coworkers ${ }^{32}$ published data on 183 matched pairs of patients who underwent CABG with either BIMA + RA with or without SV or BIMA + SV. They observed that potential long-term survival benefit could be shown with the use of RA after 10 years (HR, 0.25; 95\%
CI, 0.06-0.97; $P=.04)$, whereas at 10 years no differences were reported. In that study, the investigators incorporated the SV graft in the RA group, rendering the BIMA + RA group inhomogeneous in terms of total arterial revascularization strategy, with 152 distal anastomoses performed with the SV. Additionally, despite the application of time segment Cox regression analysis, the positive long-term survival trend over 14 years in BIMA + RA with or without SV should be cautiously interpreted, because after 10 years, the number of patients at risk were progressively reduced.

Similar conclusions were reported by Benedetto and colleagues. ${ }^{6}$ They reported comparable long-term survival (up to 17 years) in 275 matched pairs of patients who underwent CABG with either BIMA + RA with or without SV or BIMA + SV. To our knowledge, that is the largest matched series published regarding use of the RA in addition to BIMA. In that study, as in the series published by Grau and colleagues, ${ }^{32}$ some of the patients in the RA group received a SV graft (14\%). Therefore, the BIMA + RA group could not be considered homogeneous in terms of revascularization strategy. However, the survival curve comparisons between the BIMA + RA and BIMA + SV groups showed no differences when the patients with SV graft were excluded from the analysis and only those subjects who received total arterial revascularization were analyzed. On the contrary, Shi and colleagues ${ }^{7}$ recently published a relative large series of 262 matched pairs of patients showing a long-term survival advantage of RA compared with $\mathrm{SV}$ grafting at 15 years $(P=.02)$. Moreover, in the separate analysis of a comparison of the groups 
according to the territory target (RCA), patients with RA had better 15 -year survival $(P=.004)$.

Although in our study we examined a relatively small number of patients, the strength is that the BIMA and RA group represent a total arterial myocardial revascularization strategy that was compared with a mixed arterial strategy. In our study we observed that the use of the RA was not associated with early negative results and did not increase the operative risk and late negative results. However, the effect of the RA graft on in-hospital mortality could not be evaluated using logistic regression because of the very low number of death events $(n=4)$.

The incidence of deep sternal wound infections, which is recognized to be associated with BIMA harvesting, was extremely low. This is likely explained by the low incidence of insulin-dependent diabetes mellitus, chronic obstructive pulmonary disease, obesity, and reoperation for bleeding.

We found no significant difference in terms of distal anastomoses between the 2 groups. In all patients, we aimed to obtain a complete myocardial revascularization to avoid the negative effect of incomplete revascularization on late survival. ${ }^{33,34}$ However, we acknowledge that each patient had passed the surgeon's "eyeball test" for RA usage, and some of those patients with an indication to more than 3 distal anastomosis received a $\mathrm{SV}$ graft because of the reluctance by some surgeons to perform sequential anastomosis with the RA.

The mean age of the patients in this study was approximately 60 years, with $76.8 \%$ younger than 65 years. This distribution of age is in line with the recent publications. $^{6,7,31,32}$ The use of RA in addition to BIMA is a preferred coronary revascularization strategy in young patients, although it was difficult to find a univocal message in terms of long-term clinical benefit for RA conduit in the literature. However, considering that some authors have reported a trend toward improved long-term benefit of RA after 10 to 12 years, ${ }^{7,31}$ it is reasonable to expect a significant long-term benefit of BIMA + RA after 20 years. Data are lacking in the literature at this time with respect to such prolonged follow-up.

In our cohort, the role of 2 mammary artery conduits to effectively revascularize two-thirds of the myocardium might explain the lack of long-term survival benefit observed with use of the RA compared with the SV. In our clinical practice, the RA is considered a third arterial conduit, and is therefore used to graft the third most clinically significant myocardial territory. Thus, as theorized by Benedetto and colleagues ${ }^{6}$ and Mohammadi and colleagues, ${ }^{31}$ the superiority of the RA compared with the $\mathrm{SV}$ is not yet demonstrable in long-term survival in patients whose 2 most predominant myocardial territories were grafted with 2 mammary arteries. Furthermore, the site of a right coronary lesion might have a different effect on late survival depending on whether the stenosis is localized either in the proximal segment or in one of the terminal branches of the RCA, or in the case of a totally occluded RCA perfused from the left system. Unfortunately, we have no data regarding the grade of stenosis of the right and CxA and we acknowledge that this variable might affect the eligibility of patients for either the RA or SV use. There is strong evidence that grade of stenosis $<75 \%$ might negatively affect the patency of the RA and therefore this arterial graft should be considered preferably when the grade of coronary stenosis is $>90 \%{ }^{1,18}$ However, we have not ignored the potential longer patency or the RA compared with the SV and surgeons should attempt to achieve a total arterial myocardial revascularization with BIMA and the RA for patients at low perioperative risk, and with a prolonged life expectancy. Longer follow-up might highlight a significant benefit of use of the RA over the SV.

\section{Study Limitation}

This study is limited in its retrospective nature. PS analysis strongly mitigates this limitation but does not eliminate the bias of surgeon's choice of conduit. The decision to use BIMA revascularization, or a BIMA + RA strategy, is highly dependent on operator preference.

The sample size is another limitation of this study due to the relatively small number of patients. However, it is comparable with previously reported single-center studies.

Another limitation of this study is the lack of data regarding the grade of stenosis of the right and CxA. Unfortunately, we cannot include this variable in the PS model and this means caution must be used in interpreting our results in terms of long-term survival in the BIMA + RA subjects. Long-term survival data are not reinforced by angiography, preventing verification of any eventual linear correlation between patency of either the RA or the SV and survival. In our country, as well as in most European countries, the high cost of angiographic procedures, along with associated risks, limits the indications for use of postoperative coronary angiogram to clinically important reasons. Moreover, it is difficult to obtain consent from asymptomatic patients to undergo postoperative angiography.

It would have been interesting to observe the grade of coronary target lesion, the freedom from new angina, new myocardial infarction, new reoperation, and causes of late death, but we were able to analyze only the cumulative survival for all-cause mortality as an objective and unbiased end point.

\section{CONCLUSIONS}

In a relatively small population of patients with triplevessel coronary artery disease, the use of the RA as a third arterial conduit with BIMA did not negatively affect early outcome and conferred a long-term survival benefit comparable with that with the use of the SV. Further longer-term studies are required to show whether the use of the RA offer 
better long-term survival than the $\mathrm{SV}$ as a third graft in addition to BIMA.

\section{Conflict of Interest Statement}

Authors have nothing to disclose with regard to commercial support.

The authors thank Giorgia Pavan for her tireless and high-value contribution during the correction and writing of the article.

\section{References}

1. Sousa-Uva M, Neumann FJ, Ahlsson A, Alfonso F, Banning AP, Benedetto U, et al. 2018 ESC/EACTS guidelines on myocardial revascularization. Eur J Cardiothorac Surg. 2019;55:4-90.

2. Hillis LD, Smith PK, Anderson JL, Bittl JA, Bridges CR, Byrne JG, et al. 2011 ACCF/AHA guideline for coronary artery bypass graft surgery: executive summary: a report of the American College of Cardiology Foundation/American Heart Association Task Force on Practice Guidelines. J Thorac Cardiovasc Surg. 2012;143:4-34.

3. Tatoulis J. Total arterial coronary revascularization-patient selection, stenoses, conduits, targets. Ann Cardiothorac Surg. 2013;2:499-506.

4. Locker C, Schaff HV, Daly RC, Dearani JA, Bell MR, Frye RL, et al. Multiple arterial grafts improve survival with coronary artery bypass graft surgery versus conventional coronary artery bypass grafting compared with percutaneous coronary interventions. J Thorac Cardiovasc Surg. 2016;152:369-79.e4.

5. Shi WY, Hayward PA, Tatoulis J, Rosalion A, Newcomb AE, Fuller JA, et al. Are all forms of total arterial revascularization equal? A comparison of single versus bilateral internal thoracic artery grafting strategies. J Thorac Cardiovasc Surg. 2015; $150: 1526-33$

6. Benedetto U, Caputo M, Zakkar M, Bryan A, Angelini GD. Are three arteries better than two? Impact of using the radial artery in addition to bilateral internal thoracic artery grafting on long-term survival. J Thorac Cardiovasc Surg. 2016;152:862-9.e2.

7. Shi WY, Tatoulis J, Newcomb AE, Rosalion A, Fuller JA, Buxton BF. Is a third arterial conduit necessary? Comparison of the radial artery and saphenous vein in patients receiving bilateral internal thoracic arteries for triple vessel coronary disease. Eur J Cardiothorac Surg. 2016;50:53-60.

8. Formica F, Ferro O, Greco P, Martino A, Gastaldi D, Paolini G. Long-term follow-up of total arterial myocardial revascularization using exclusively pedicle bilateral internal thoracic artery and right gastroepiploic artery. Eur J Cardiothorac Surg. 2004;26:1141-8.

9. Formica F, Greco P, Colagrande L, Martino A, Corti F, Ferro O, et al. Right gastroepiploic artery graft: long-term clinical follow-up in 271 patients-experience of a single center. J Card Surg. 2006;21:539-44.

10. Suma H, Tanabe H, Takahashi A, Horii T, Isomura T, Hirose H, et al. Twenty years experience with the gastroepiploic artery graft for CABG. Circulation. 2007;116(11 suppl):I188-91.

11. Gaudino M, Puskas JD, Di Franco A, Ohmes LB, Iannaccone M, Barbero U, et al. Three arterial grafts improve late survival: a meta-analysis of propensitymatched studies. Circulation. 2017;135:1036-44.

12. Yanagawa B, Verma S, Mazine A, Tam DY, Jüni P, Puskas JD, et al. Impact of total arterial revascularization on long term survival: a systematic review and meta-analysis of 130,305 patients. Int J Cardiol. 2017;233:29-36.

13. Martinez-Gonzale B, Reyes-Hernandez CG, Quiroga-Garza A, RodriguezRodriguez VE, Esparza-Hernandez CN, Olizondo-Omana RE, et al. Conduits used in coronary artery bypass grafting: a review of morphological studies. Ann Thorac Cardiovasc Surg. 2017;23:55-65.

14. Schwann TA, El Hage Sleiman AK, Yammine MB, Tranbaugh RF, Engoren M, Bonnell MR, et al. The incremental value of three or more arterial grafts in CABG: the effect of native vessel disease. Ann Thorac Surg. 2018;106:1071-8.

15. Aldea GS, Bakaeen FG, Pal J, Fremes S, Head SJ, Sbik J, et al. The Society of Thoracic Surgeons clinical practice guidelines on arterial conduits for coronary artery bypass grafting. Ann Thorac Surg. 2016;101:801-9.

16. Collins P, Webb CM, Chong CF, Moat NE. Radial Artery Versus Saphenous Vein Patency (RSVP) Trial Investigators. Radial artery versus saphenous vein patency randomized trial: five-year angiographic follow-up. Circulation. 2008;117: 2859-64.

17. Deb S, Cohen EA, Singh SK, Une D, Laupacis A, Fremes SE, et al. Radial artery and saphenous vein patency more than 5 years after coronary artery bypass surgery: results from RAPS (Radial Artery Patency Study). J Am Coll Cardiol. 2012; 60:28-35.

18. Hayward PA, Gordon IR, Hare DL, Matalanis G, Horrigan ML, Rosalion A, et al Comparable patencies of the radial artery and right internal thoracic artery of saphenous vein beyond 5 years: results from the Radial Artery Patency and Clinical Outcomes trial. J Thorac Cardiovasc Surg. 2010;139:60-5.

19. Lauer MS, Blackstone EH, Young JB, Topol EJ. Cause of death in clinical research: time for a reassessment? J Am Coll Cardiol. 1999;34:618-20.

20. Austin PC. Optimal caliper widths for propensity-score matching when estimating differences in means and differences in proportions in observational studies. Pharm Stat. 2011;10:150-61.

21. Collins GS, Le Manach Y. Comparing treatment effects between propensity scores and randomized controlled trials: improving conduct and reporting. Eur Heart J. 2012;33:1867-9.

22. Austin AC. Propensity-score matching in the cardiovascular surgery literature from 2004 to 2006: a systematic review and suggestions for improvement. J Thorac Cardiovasc Surg. 2007;134:1128-35.

23. Benedetto U, Head SJ, Angelini GD, Blackstone EH. Statistical primer: propensity score matching and its alternatives. Eur J Cardiothorac Surg. 2018;53: $1112-27$.

24. Gaudino M, Benedetto U, Fremes S, Biondi-Zoccai G, Sedrakyan A, Puskas JD et al. Radial-artery or saphenous-vein grafts in coronary-artery bypass surgery. $N$ Engl J Med. 2018;378:2069-77.

25. Locker C, Schaff HV, Dearani JA, Joyce LD, Park SJ, Burkhart HM, et al. Multiple arterial grafts improve late survival of patients undergoing coronary artery bypass graft surgery: analysis of 8622 patients with multivessel disease. Circulation. 2012;126:1023-30.

26. Medalion B, Mohr R, Ben-Gal Y, Nesher N, Kramer A, Eliyahu S, et al. Arteria coronary artery bypass grafting is safe and effective in elderly patients. $J$ Thorac Cardiovasc Surg. 2015;150:607-12.

27. Mastrobuoni S, Gawad N, Price J, Chan V, Ruel M, Mesana TG, et al. Use of bilateral internal thoracic artery during coronary artery bypass graft surgery in Canada: the bilateral internal thoracic artery survey. J Thorac Cardiovasc Surg. 2012;144:874-9.

28. Iribarne A, Goodney PP, Flores AM, DeSimone J, Di Scipio AW, Austin A, et al National trends and geographic variation in bilateral internal mammary artery use in the United States. Ann Thorac Surg. 2017;104:1902-7.

29. Kappetein AP, Dawkins KD, Mohr FW, Morice MC, Mack MJ, Russell ME, et al. Current percutaneous coronary intervention and coronary artery bypass grafting practices for three-vessel and left main coronary artery disease. Insights from the SYNTAX run-in phase. Eur J Cardiothorac Surg. 2006;29:486-91.

30. Di Mauro M, Contini M, Iacò AL, Bivona A, Gagliardi M, Varone E, et al. Bilateral internal thoracic artery on the left side: a propensity score-matched study of impact of the third conduit on the right side. J Thorac Cardiovasc Surg. 2009; 137:869-74.

31. Mohammadi S, Dagenais F, Voisine P, Dumont E, Charbonneau E, Marzouk M, et al. Impact of the radial artery as an additional arterial conduit during in-situ bilateral internal mammary artery grafting: a propensity score-matched study Ann Thorac Surg. 2016:101:913-8.

32. Grau JB, Kuschner CE, Johnson CK, Ferrari G, Zapolanski A, Brizzio ME, et al The effects of using a radial artery in patients already receiving bilateral internal mammary arteries during coronary bypass grafting: 30-day outcomes and 14year survival in a propensity-matched cohort. Eur J Cardiothorac Surg. 2016; 49:203-10.

33. Benedetto U, Caputo M, Patel NN, Fiorentino F, Bryan A, Angelini GD. Longterm survival after off-pump versus on-pump coronary artery bypass graft surgery. Does completeness of revascularization play a role? Int J Cardiol. 2017; 246:32-6.

34. Omer S, Cornwell LD, Rosengart TK, Kelly RF, Ward HB, Holman WL, et al. Completeness of coronary revascularization and survival: impact of age and off-pump. J Thorac Cardiovasc Surg. 2014;148:1307-15.

Key Words: radial artery, bilateral internal mammary arteries, total arterial myocardial revascularization, $\mathrm{CABG}$ 